\title{
Revision of the Australian genus Logasa Chandler (Staphylinidae, Pselaphinae, Faronitae) with description of three new species
}

\author{
Jun-Young Kang', Donald S. Chandler², Jong-Seok Park' \\ I Chungbuk National University, 1 Chungdae-ro, Seowon-gu, Cheongju-si, Chungbuk-do 28644, South Ko- \\ rea 2 Department of Biological Sciences, University of New Hampshire, Durham, NH 03824, USA \\ Corresponding author:Jong-Seok Park (jpark16@cbnu.ac.kr) \\ Academic editor: Adam Brunke | Received 26 August 2019 | Accepted 2 October 2019 | Published 5 November 2019 \\ http://zoobank.org/A9D064BE-8DBA-4739-96F7-5D33708CE744 \\ Citation: Kang J-Y, Chandler DS, Park J-S (2019) Revision of the Australian genus Logasa Chandler (Staphylinidae, \\ Pselaphinae, Faronitae) with description of three new species. ZooKeys 886: 145-154. https://doi.org/10.3897/ \\ zookeys.886.39446
}

\begin{abstract}
The Australian genus Logasa Chandler, 2001 (type species: L. novaeanglia Chandler) is comprised of six species, three of which are described as new: Logasa newtoni sp. nov., Logasa thayerae sp. nov., and Logasa comforti sp. nov. Examination of the types of L. tricolor (Oke) and L. ventralis (Oke) revealed that they do not share some of the diagnostic characters used here to characterize the type, and other species of the genus, but they are retained in Logasa until the group is revised. A key to species, illustrations of their habitus, and diagnostic characters are provided.
\end{abstract}

\section{Keywords}

beetle, biodiversity, biogeography, systematics, taxonomy

Copyright Jun-Young Kang et al. This is an open access article distributed under the terms of the Creative Commons Attribution License (CC BY 4.0), which permits unrestricted use, distribution, and reproduction in any medium, provided the original author and source are credited. 


\section{Introduction}

The Australian genus Logasa Chandler was described in 2001 based on Logasa novaeanglia Chandler. Two other species, L. tricolor (Oke, 1928) and L. ventralis (Oke, 1928), were originally described in the genus Sagola (Oke, 1928), and were transferred to Logasa by Chandler (2001). During our revisionary study based on 140 specimens, three new species were recognized. After examination of the types of $L$. tricolor and $L$. ventralis, we found that at the generic level they have different useful diagnostic characters that are based on their foveal system and the form of the male genitalia. This combination of features has not been seen in any of the existing known faronite genera. The Australian faronite fauna has numerous undescribed species (Park and Chandler 2017), which will become the targets of further studies of this very rich fauna. In this study, L. tricolor and L. ventralis are retained in the genus Logasa, but are not further treated here as they may be placed in a new genus once a subsequent revisionary study is conducted with the discovery of additional specimens of these two species.

\section{Materials and methods}

One hundred and forty specimens were examined. They are deposited in the following collections:
ANIC Australian National Insect Collection, Canberra, ACT, Australia;
CBNUIC Chungbuk National University Insect Collection, Cheongju, South Korea;
FMNH Field Museum of Natural History, Chicago, IL, USA;
MV Museum of Victoria, Melbourne, Victoria, Australia;
QM Queensland Museum, South Brisbane, Queensland, Australia;
UNHC University of New Hampshire Insect Collection, Durham, NH, USA.

One specimen of each species was mounted on a permanent microscope slide to observe the internal characters and fine external characters that are not apparent when using a dissecting microscope. Permanent microscopic slides were prepared using the techniques described by Hanley and Ashe (2003). Terminology and nomenclature for the descriptions follow Chandler (2001). Paired structures such as fovea are treated as singular. The morphological right and left of parameres refer to orientation on the illustrations. Decimal degrees were used for the format of geographical coordinates. Holotypes are deposited in ANIC, and paratype depositions are indicated parenthetically. Specimen label data for the holotypes is transcribed verbatim. Data for paratypes are standardized for consistency. The map of Australia is based on an image from SimpleMappr (Shorthouse 2010) that was subsequently modified to add locality marks. 


\section{Systematics}

Family Staphylinidae Latreille, 1802

Subfamily Pselaphinae Latreille, 1802

Supertribe Faronitae Reitter, 1882

Genus Logasa Chandler, 2001

http://zoobank.org/14006A6B-F528-41B1-94FF-03871A4617C5

Logasa Chandler, 2001: 47.

Type species. Logasa novaeanglia Chandler (designated by Chandler 2001: 47).

Diagnosis. Members of this genus are easily separated from other faronite genera by the following combination of characters: head with long frontal sulcus, closed anteriorly (Fig. 2a); elytra rectangular and longer than wide, hind wings fully developed (Fig. 1a-d); mesoventrite with lateral mesosternal fovea, promesocoxal fovea, and lateral mesocoxal fovea (Fig. 2b), and round setal patch at center (Fig.
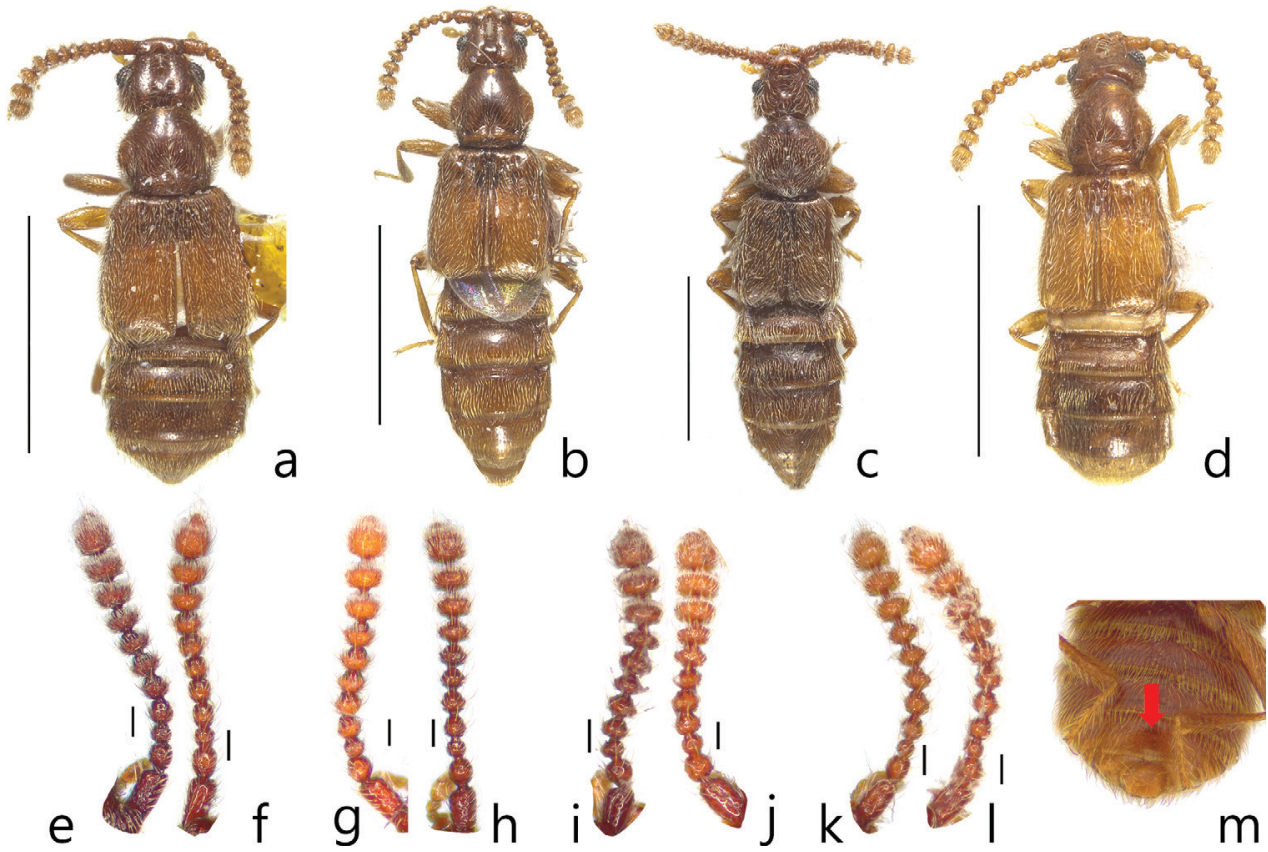

Figure I. Habitus figures, dorsal view a Logasa novaeanglia Chandler b L. newtoni sp. nov. c L. thayerae sp. nov. d L. comforti sp. nov. Antennae L. novaeanglia Chandler: e male f female L. newtoni sp. nov.: $\mathbf{g}$ male $\mathbf{h}$ female $L$. thayerae sp. nov.: i male $\mathbf{j}$ female $L$. comforti sp. nov.: $\mathbf{k}$ male $\mathbf{I}$ female. Male abdominal venter of $L$. comforti sp. nov. $\mathbf{m}$ setose depression (arrow). Scale bars: $1 \mathrm{~mm}(\mathbf{a}-\mathbf{d}), 0.1 \mathrm{~mm}(\mathbf{e}-\mathbf{l})$. 
2b: arrow); metaventrite with metasternal fovea and median metasternal fovea (Fig. 2b); male abdominal ventrite VIII with setose depression (Fig. $1 \mathrm{~m}$ ) located at middle; abdominal ventrites without basolateral fovea; length of abdominal ventrites and tergites VI-VII longer than others (Fig. 1a-d); female abdominal ventrite IX with two pairs of long setae (Fig. 2c); parameres of male genitalia asymmetric and shorter than apical lobe (Fig. 3a-d); phallobase of median lobe rounded and asymmetric (Fig. 3a-d).

Distribution. Southeast Australia (New South Wales, Victoria, Tasmania).

Comments. All specimens, both male and female, of the genus Logasa have fully-developed hind wings, and many specimens were collected by flight intercept traps. Members of this genus are usually found in temperate or rainforest habitats in southeastern Australia. Male specimens have a setose depression located at the middle of abdominal ventrite VIII as a secondary sexual character, but this is not easily observed on some specimens. Abdominal ventrite IX is important for recognizing the sex of specimens: in males ventrite IX is usually fragile and partially concealed by ventrite VIII; in females it is more robust, triangular and bears a pair of long setae (Park and Carlton 2014).

\section{Key to species of the genus Logasa Chandler}

The key is mainly based on male genitalia because most species are indistinguishable based on external morphology.

$1 \quad$ Antennomeres II and IV subquadrate (Fig. 1i-j); right paramere of male genitalia divided into two lobes (Fig. 3c, long arrow); found in Tasmania and Victoria (Fig. 4: triangle)

Logasa thayerae sp. nov. Antennomeres II and IV longer than wide (Fig. 1e-h, k-l); right paramere of male genitalia not divided (Fig. 3a-b, d) .2

2 Apical portion of median lobe of male genitalia not branched (Fig. 3b); left paramere of male genitalia curved to left (Fig. 3b, short arrow); found in New South Wales and Victoria (Fig. 4: circle) L. newtoni sp. nov.

- $\quad$ Apical portion of median lobe of male genitalia branched (Fig. 3a, d); left paramere of male genitalia less curved (Fig. 3a, d) ......

3 Apical lobe of male genitalia forked into two lobes, major lobe longer than three branches (Fig. 3a); right paramere of male genitalia twice as wide as left (Fig. 3a); found in New South Wales (Fig. 4: square)

L. novaeanglia Chandler

- $\quad$ Apical lobe of male genitalia with three branches extending from right side (Fig. 3d); right paramere of male genitalia slightly broader than left or as wide as left (Fig. 3d); found in Tasmania and Victoria (Fig. 4: diamond). 


\section{Logasa novaeanglia Chandler, 2001}

http://zoobank.org/CC8FB01A-83D3-4674-8D98-BF2E4441FAE7

Logasa novaeanglia Chandler, 2001: 49.

Type material examined. Paratypes ( $N=16 ; 5$ males, 11 females). Australia: New South Wales (NSW): $1 \sigma^{\widehat{\lambda}}$ (aedeagus dissected and placed in micro-vial, UNHC), New England National Park, Wright's Lookout Trail, 1300 m, 27 II-6 III 1980, Nothofagus

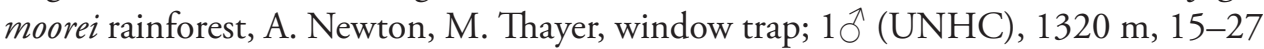
II 1993, D. S. Chandler, FIT, cool temperate rainforest; 1 + (UNHC), 2-17 IV 1993, D. S. Chandler, FIT, cool temperate rainforest; 19 (UNHC), 28 II-14 III 1993, D. S. Chandler, FIT, cool temperate rainforest; 1 ( (UNHC), 1330 m, 17 V 1993, D.S.

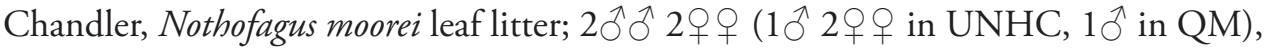
Styx River State Forest, Cedar Pit Floral Reserve, $42 \mathrm{~km}$ south east Wollomombi, 935

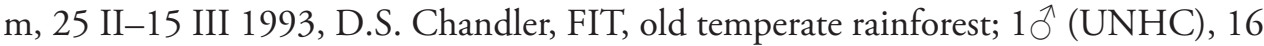
III-4 IV 1994, D.S. Chandler, FIT, old temperate rainforest; 1 ㅇ (UNHC), 3-15 II 1993, K. MacGregor, FIT, old temperate rainforest; 1 ㅇ (ANIC), 20 IV-12 V 1993, D.S. Chandler, FIT, old temperate rainforest; $1 \delta^{\hat{\gamma}}$ (UNHC), $40 \mathrm{~km}$ south east Wollomombi, 990 m, 16 III-4 IV 1993, D.S. Chandler, FIT, old wet sclerophyll; 1 q (ANIC), 2-14 XII 1993, K. MacGregor, FIT, old wet sclerophyll; 1 ㅇ (ANIC), 6 XI-1 XII 1993, K. MacGregor, FIT, old wet sclerophyll; 1 ㅇ (ANIC), 25 II-15 III 1993, D.S. Chandler, FIT, old wet sclerophyll; 1 ㅇ (ANIC), 15 X-5 XI 1993, K. MacGregor, FIT, old wet sclerophyll.

Additional materials $(N=26 ; 10$ males, 16 females). Australia: NSW: $60 \hat{\sigma}$

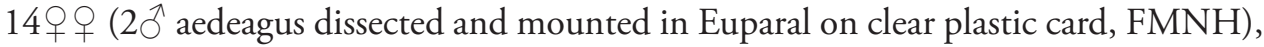
New England National Park, Robinson's Knob Road, 1 km east Park Gate, 1320 m, 30.30S, 152.24E, 29 XII 1986-14 I 1987, Nothofagus moorei forest, A. Newton \& M. Thayer 781, FMHD\#86-689, FIT \& window; $10^{\Uparrow}$ (FMNH), $1305 \mathrm{~m}$; 30.30S, 152.24E, 29 XII 1986, Nothofagus moorei forest, A. Newton \& M. Thayer 780, FMHD\#86-688, berlese, leaf \& $\log$ litter, forest floor; $30 \widehat{\jmath} 29+$ (CBNUIC), 29 XII 1986-14 I 1987, Nothofagus moorei forest, A. Newton \& M. Thayer 780, FMHD\#86686, flight intercept (window) trap.

Diagnosis. This species can be distinguished from the other species of the genus Logasa by the following combination of characters: antennomeres II and IV rectangular and longer than wide (Fig. 1e-f), apical lobe of male genitalia forked into two lobes, major lobe longer with three branches, parameres with over ten setae, and right lobe shorter and wider (Fig. 3a).

Description. Length 2.1-2.5 mm. Body yellowish to reddish-brown (Fig. 1a). Head. Head triangular with frontal fovea and vertexal foveae. Antennomeres with tubercles and long setae (Fig. 1e-f). Antennomere I elongate, II rectangular, III subquadrate and smallest, IV rectangular, V rhombic, VI-X gradually transverse (Fig. 1e-f). Tho- 


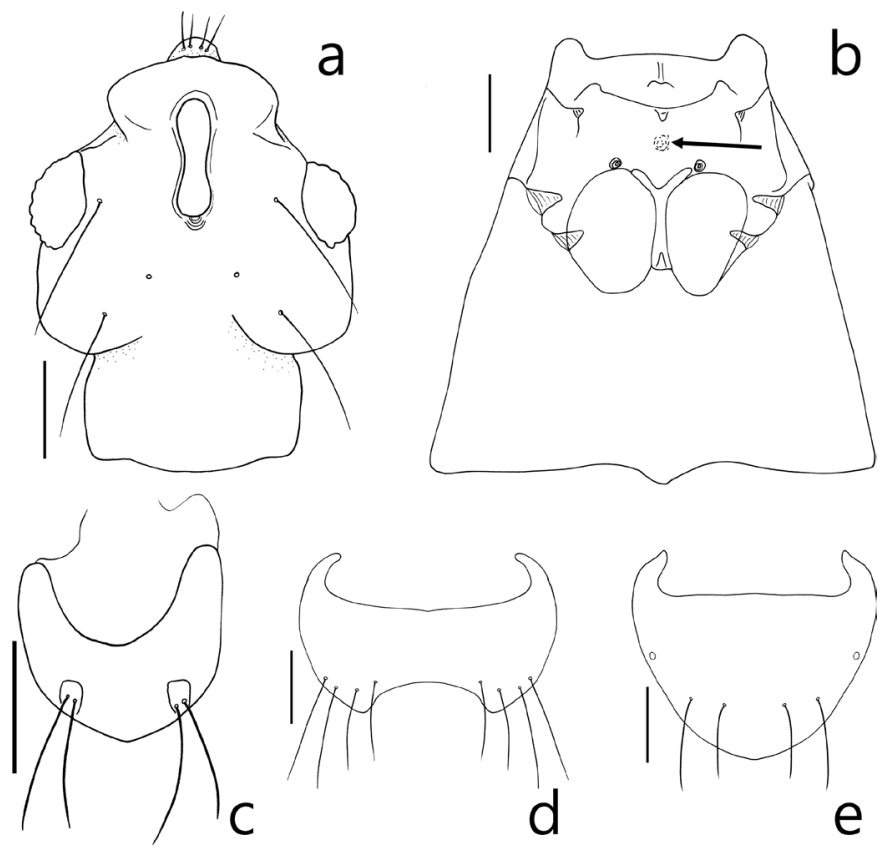

Figure 2. Logasa newtoni sp. nov. a head, dorsal view $\mathbf{b}$ meso- and metaventrite, ventral view $\mathbf{c}$ female abdominal ventrite IX, ventral view $\mathbf{d}$ male abdominal ventrite VIII, ventral view e male abdominal tergite VIII, dorsal view. Scale bar: $0.1 \mathrm{~mm}$.

rax. Pronotum with deep sulcus and pair of lateral antebasal foveae. Each elytron with basal elytral foveae and discal elytral foveae. Abdomen. Tergite IV with pair of transverse patches of microtrichia (Fig. 1a). Aedeagus. Apical lobe of male genitalia forked into two lobes, major lobe longer with three branches, minor lobe short and simple (Fig. 3a). Phallobase of median lobe asymmetric and rounded (Fig. 3a). Parameres asymmetric with over ten setae, left paramere longer and narrower than right (Fig. 3a).

Distribution. New South Wales (Fig. 4: square).

Habitat. Specimens of this species were collected using flight intercept traps, window traps, or by sifting leaf and log litter in wet sclerophyll forests.

\section{Logasa newtoni Kang, Chandler \& Park, sp. nov.}

http://zoobank.org/66785C9A-2DA5-4593-A9EA-BB78B2DA22AA

Type material. Holotype. Australia: NSW: $\widehat{\overbrace{}}$ (ANIC), "AUSTRALIA: NSW., / Brown Mtn. Floral / Res., 0.5 km SSW / Cochrane Dam, 940 m" "II - 8/ 22 - 1993 / A Newton \& M Thayer / cool temp. rainfor / window trap". Paratypes $(N=83$; 25 males, 58 females). Australia: NSW: $1{ }^{\Uparrow} 2 q q$ (FMNH), Brown Mountain Flora Reserve, 0.5 km SSW Cochrane Dam, 950 m, 36.35S, 149.27E, 20 XII 1986, warmtemperate rainforest, A. Newton \& M. Thayer 767, FMHD \#86-650, berlese, leaf \& 

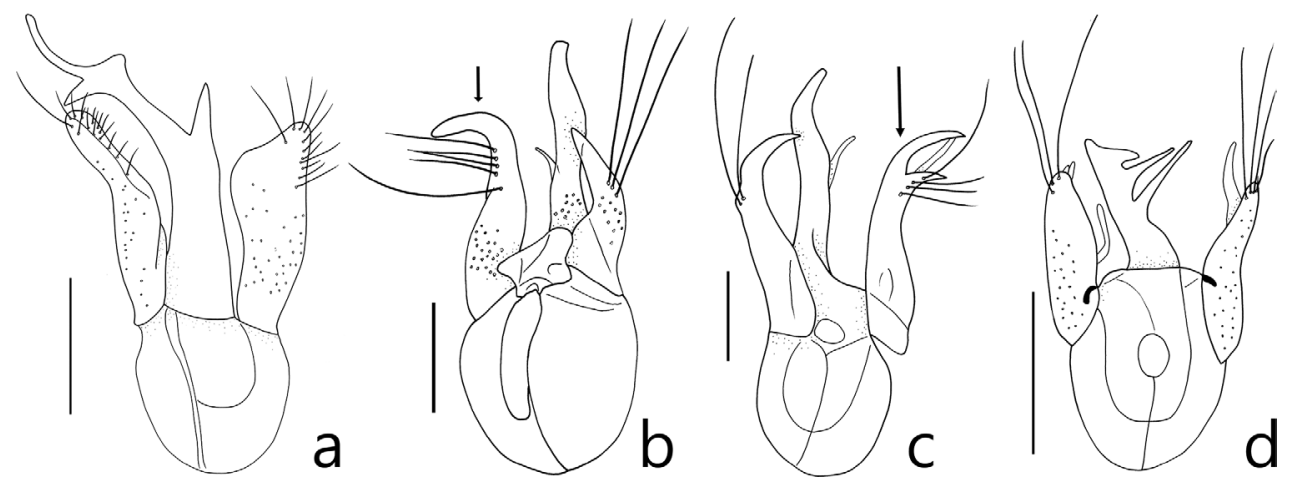

Figure 3. Aedeagi, dorsal view a Logasa novaeanglia Chandler b $L$. newtoni sp. nov. c $L$. thayerae sp. nov. d $L$. comforti sp. nov. Scale bar: $0.1 \mathrm{~mm}$.

$\log$ litter, forest floor; $6 \hat{\partial} \hat{\partial} 41$ 우 $(3 \hat{0} \hat{o}$ aedeagus dissected and mounted in Euparal on clear plastic card, 1 ㅇ slide mounted, FMNH), 20 XII 1986-15 II 1987, warmtemperate rainforest, A. Newton \& M. Thayer 767, FMHD\#86-648, FIT \& window;

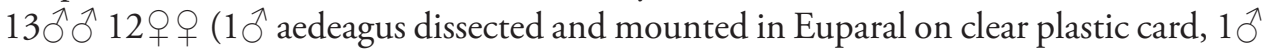

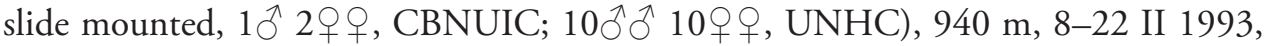
A. Newton \& M. Thayer, cool temperate rainforest, window trap; 3 우 (UNHC), Brown Mountain, 853 m, 30 III 1967, rainforest, RWT, RJB, ANIC Berlesate No. 20 leafmould; $1 \hat{\delta}$ (aedeagus dissected and placed in micro-vial, left paramere damaged, ANIC), ca. 914 m, 9 XII 1967, rainforest, Taylor \& Brooks, ANIC Berlesate No. 42 leafmould; $10^{\widehat{\lambda}}$ (aedeagus dissected and placed in micro-vial, left paramere damaged, ANIC), Rutherford Creek, 9 I 1968, rainforest, M. Upton, ANIC Berlesate No. 55

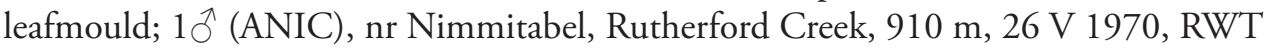
$\&$ R. Bartell, rainforest, ANIC Berl. \#287; Victoria (VIC): $10^{\Uparrow}$ (aedeagus dissected and mounted in Euparal on clear plastic card, MV), Road C187, $15 \mathrm{~km}$ west Dartmoor, 1 VIII 2012, ground moss, blackwood stringybark forest.

Diagnosis. This species can be distinguished from the other Logasa species by the following combination of characters: antennomeres II and IV rectangular and longer than wide (Fig. 1g-h), apical lobe of male genitalia not divided, left paramere of male genitalia curved to left (Fig. 3b).

Description. Length 1.6-2.5 mm. Body yellowish to reddish-brown (Fig. 1b). Head. Head triangular with frontal fovea and vertexal foveae. Antennomeres with tubercles and long setae (Fig. 1g-h). Antennomere I elongate, II rectangular, III subquadrate and smallest, IV rectangular, V-VII rhombic, VIII-X gradually transverse (Fig. 1g-h). Thorax. Pronotum with deep sulcus and pair of lateral antebasal foveae. Each elytron with basal elytral foveae and discal elytral foveae. Abdomen. Tergite IV with pair of transverse patches of microtrichia (Fig. 1b). Aedeagus. Apical lobe of male genitalia not branched (Fig. 3b). Phallobase of median lobe asymmetrical and rounded (Fig. 3b). Parameres of male genitalia asymmetrical, left longer than right and curved to left (Fig. 3b). 
Distribution. New South Wales, Victoria (Fig. 4: circle).

Etymology. This species is named for one of the co-collectors of the holotype and world-renowned beetle specialist, Alfred F. Newton.

Habitat. Most specimens of this species were collected using flight intercept traps, window traps, or by sifting leaf and log litter in temperate forest or rainforest habitats.

\section{Logasa thayerae Kang, Chandler \& Park, sp. nov.} http://zoobank.org/E70F5324-AF5F-4A20-9B1D-DC613B4A08FB

Type material. Holotype. Australia: VIC: $\delta$ (MV), aedeagus dissected in micro-vial, "AUSTRL.: VIC.: Otway N.P., / Malts Rest, 260 m / 38.45S 143.33E / 25.I-8. II.1987 / wet scleroph. - Noth. cunn." "A. Newton \& M. Thayer 807 / FMHD \#87206 / flight intercept / (window) trap". Paratypes ( $N=6 ; 2$ males, 4 females). Aus-

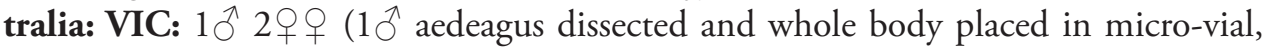
1 ㅇ slide mounted, UNHC), $10 \mathrm{~km}$ east of Maryville, 27 XI 1986, D. Burckhardt; 1 ㅇ (UNHC), Belgrave, V.F.E. Wilson, I 1922, fallen leaves (MV); Australia: Tasmania (TAS): $1 \hat{\jmath}$ (aedeagus dissected and whole body placed in micro-vial, MV), Zeehan, 16 IV 1895; 1 ㅇ (MV), Mt. Wellington, I 1948, C. Oke.

Diagnosis. This species can be distinguished from the other Logasa species by the following combination of characters: antennomeres II and IV subquadrate (Fig. 1i-j), apical lobe of male genitalia not divided, left paramere of male genitalia curved to right, and right paramere divided into two lobes apically and curved to right (Fig. 3c).

Description. Length 2.0-2.3 mm. Body yellowish to reddish-brown with long setae (Fig. 1c). Head. Head triangular with frontal fovea and vertexal foveae. Antennomeres with tubercles and long setae (Fig. 1i-j). Antennomere I elongate, II-IV subquadrate, III smallest, V-VI rhombic, VII-X gradually transverse (Fig. 1i-j). Thorax. Pronotum with the deep sulcus and pair of lateral antebasal foveae. Each elytron with basal elytral foveae and discal elytral foveae. Abdomen. Tergite IV with patches of microtrichia (Fig. 1c). Aedeagus. Apical lobe of male genitalia not branched (Fig. 3c). Phallobase of median lobe asymmetrical and rounded (Fig. 3c). Left parameres of male genitalia curved to right (Fig. 3c). Right paramere divided into two lobes apically and curved to right (Fig. 3c).

Distribution. Tasmania, Victoria (Fig. 4: triangle).

Etymology. This species is named for one of the co-collectors of the holotype and world-renowned beetle specialist, Margaret K. Thayer.

Habitat. Most specimens of this species were collected using flight intercept (window) traps in wet sclerophyll forests.

\section{Logasa comforti Kang, Chandler \& Park, sp. nov.} http://zoobank.org/5268E63A-440F-4E4B-B861-078605AA90E3

Type material. Holotype. Australia: TAS: $\delta$ (ANIC), "43.25S 146.10E TAS / Melaleuca near / Bathurst Harbour / 15 Apr.-29 May 1991 / M. Comfort F.I.T.\#1", "F.I.T. / 
ANIC 1185 / closed forest”. Paratypes ( $N=6 ; 3$ males, 3 females). Australia: TAS: $1 \delta$ 1 오 (ANIC), Melaleuca near Bathurst Harbour, 43.25S, 146.10E, 15 IV-29 V 1991, M. Comfort, FIT\#1, ANIC 1185, closed forest; 19 (ANIC), 29 V-29 VIII 1991, M. Comfort, FIT\#1, ANIC 1190, closed forest; $1 \delta^{\Uparrow}$ (aedeagus dissected and mounted in Euparal on clear plastic card, ANIC), 29 VIII-28 XI 1991, I. Naumann \& G. Clarke, FIT\#1, closed forest, ANIC 1202; 1 ㅇ (ANIC), 15 III-15 IV 1991, E. Edwards, J. Berry, FIT\#1, ANIC 1179, closed forest; VIC: $1 \widehat{\jmath}$ (aedeagus dissected in micro-vial, MV), Ballarat, C. Oke.

Diagnosis. This species can be distinguished from the other Logasa species by the following combination of characters: antennomeres II and IV rectangular and longer than wide (Fig. $1 \mathrm{k}-\mathrm{l}$ ), apical lobe of male genitalia with three branches bearing to right, left paramere broader than right (Fig. 3d).

Description. Length 1.6-1.9 mm. Body yellowish to reddish-brown (Fig. 1d). Head. Head triangular with frontal fovea and vertexal foveae. Antennomeres with tubercles and long setae (Fig. 1k-1). Antennomere I elongate, II rectangular, III subquadrate, IV rectangular, V-VI rhombic, VII-X gradually transverse (Fig. $1 \mathrm{k}-\mathrm{l}$ ). Thorax. Pronotum with deep and distinct pit in the middle and lateral antebasal foveae. Each elytron with basal elytral foveae and discal elytral foveae. Abdomen. Tergite IV with patches of microtrichia (Fig. 1d). Aedeagus. Apical lobe of male genitalia with three branches bearing to right (Fig. 3d). Phallobase of aedeagus asymmetric and rounded (Fig. 3d). Left paramere broader than right (Fig. 3d).

Distribution. Tasmania, Victoria (Fig. 4: diamond).

Etymology. This species is named for the collector of the holotype, C. Comfort.

Habitat. Most specimens of this species were collected using flight intercept traps in forests.

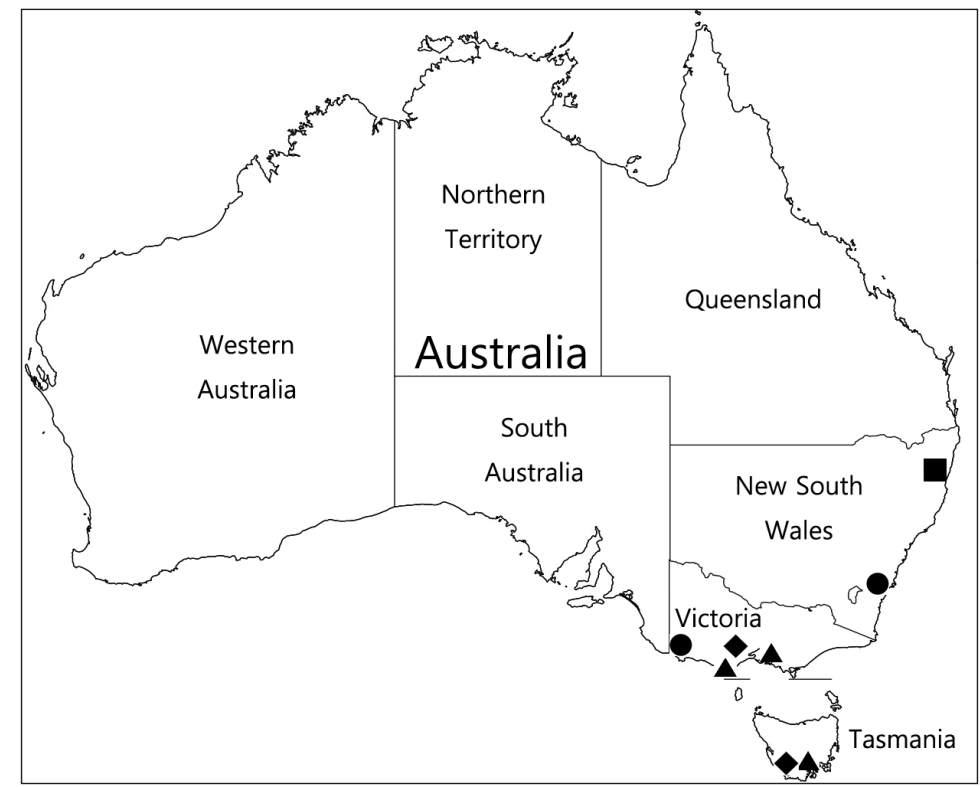

Figure 4. Collection localities of Logasa novaeanglia Chandler: square L. newtoni sp. nov.: circle L. thayerae sp. nov.: triangle $L$. comforti sp. nov.: diamond. 


\section{Acknowledgements}

We thank Margaret K. Thayer and Alfred Newton (Field Museum Natural History, Chicago, Illinois) for the loan of valuable specimens. Comments of anonymous reviewers guided substantial improvements to the manuscript. This work was supported by a research grant of the Chungbuk National University in 2017, and was further supported by a grant from the National Institute of Biological Resources (NIBR), funded by the Ministry of Environment (MOE) of the Republic of Korea (NIBR201928201).

\section{References}

Chandler DS (2001) Biology, Morphology, and Systematics of the Ant-like Litter Beetle Genera of Australia (Coleoptera: Staphylinidae: Pselaphinae). Memoirs on Entomology, International, Associated Publishers, Florida, 560 pp.

Hanley RS, Ashe JS (2003) Techniques for dissecting adult aleocharine beetles (Coleoptera: Staphylinidae). Bulletin of Entomological Research 93: 11-18. https://doi.org/10.1079/ BER2002210

Oke C (1928) Notes on Australian Coleoptera, with descriptions of new species. Proceedings of the Linnean Society of New South Wales 53(1): 1-30. https://doi.org/10.5962/bhl. part.26052

Park JS, Carlton CE (2014) A revision of the New Zealand species of the genus Sagola Sharp (Coleoptera: Staphylinidae: Pselaphinae: Faronitae). The Coleopterists Society Monograph Number 13: 1-156. https://doi.org/10.1649/072.068.0mo4.1

Park JS, Chandler DS (2017) Nornalup, a new genus of pselaphine staphylinid beetles from southwestern Australia (Coleoptera, Staphylinidae, Pselaphinae, Faronitae). Zookeys 695: 111-121. https://doi.org/10.3897/zookeys.695.19906

Shorthouse DP (2010) SimpleMappr, an online tool to produce publication-quality point maps. http://www.simplemappr.net [September 24, 2019] 